\title{
Effect of nicergoline on cerebral blood flow
}

\author{
L. D. ILIFF, G. H. DU BOULAY, JOH N A R S A L L, \\ R. W. ROSS RUSSELL, A N L I N D A Y S Y M O N \\ From the Institute of Neurology, National Hospital, Queen Square, London
}

SUMMARY Cerebral blood flow (CBF) was measured before and after intravenous injection of the cerebral vasodilator nicergoline in 13 patients with cerebrovascular disease. CBF increased in seven. The possibility that the effect of the drug in the remainder may have been masked by a fall of $\mathrm{CBF}$ which occurs during sequential measurement of patients at rest is discussed.

Nicergoline (1, 6-dimethyl-8 beta- (5-bromonicotinoyl-oxymethyl) -10 alpha-methoxy-ergoline) is an alpha-adrenergic receptor blocking agent (Arcari et al., 1968) which affects cerebral blood flow by reducing cerebrovascular resistance (Benzi et al., 1971). The present study was undertaken to assess the acute effect of the drug on cerebral blood flow and blood pressure in patients with cerebrovascular disease.

\section{Methods}

Thirteen patients (10 with multi-infarct dementia of moderate degree and three with transient ischaemic attacks) gave informed consent to measurement of cerebral blood flow before and after intravenous injection of $2 \mathrm{mg}$ nicergoline, using the intracarotid ${ }^{133}$ Xenon technique developed by Wilkinson et al. (1969). The studies were performed under general anaesthesia before cerebral angiography carried out for diagnostic purposes. Anaesthesia was induced by methohexitone and acoline, and maintained by nitrous oxide and oxygen supplemented by phenoperidine. Cerebral blood flow was estimated from the slope of the first two minutes of the semilogarithmic display of the clearance curve described by Olesen et al. (1971). $\mathrm{PaCO}_{2}$ and blood pressure were monitored throughout. A first estimation of cerebral blood flow was made not less than 30 minutes after induction of anaesthesia. A second estimation was made 30 minutes after the first at varying times after intravenous injection of nicergoline.

Address for reprint requests: Professor John Marshall, University Department of Clinical Neurology, The National Hospital, Queen Square, London WC1N 3BG.

Accepted 24 February 1977

\section{Results}

Cerebral blood flow was measured at times ranging from two to $20 \mathrm{~min}$ after intravenous injection of $2 \mathrm{mg}$ nicergoline; the results are given in the Table. In no case did the $\mathrm{PaCO}_{2}$ vary by more than $2.0 \mathrm{mmHg}$ between the pre- and postinjection measurements of cerebral blood flow. Blood pressure fell by not more than $10 \mathrm{mmHg}$ in all but one case in which it rose by $10 \mathrm{mmHg}$. The cerebral blood flow showed an increase in seven cases, a decrease in four, and was unchanged in two.

\section{Discussion}

The finding in seven out of 13 cases of an increase in cerebral blood flow, without significant change

Table Cerebral blood flow before and after $2 \mathrm{mg}$ nicergoline intravenously

\begin{tabular}{|c|c|c|c|c|}
\hline \multirow[t]{2}{*}{ Patient } & \multirow{2}{*}{$\begin{array}{l}\text { Time after } \\
\text { nicergoline } \\
\text { of second } \\
\text { CBF } \\
\text { measurement } \\
\text { (min) }\end{array}$} & \multicolumn{3}{|c|}{ Cerebral blood flow } \\
\hline & & $\begin{array}{l}\text { Before } \\
\text { nicergoline }\end{array}$ & $\begin{array}{l}\text { After } \\
\text { nicergoline }\end{array}$ & $\%$ change \\
\hline 1 & 2 & 35.3 & 43.7 & +23 \\
\hline 2 & 2 & 24.6 & 20.3 & -20 \\
\hline 3 & 2 & 23.0 & 20.5 & -9 \\
\hline 4 & 10 & 31.7 & 47.8 & +50 \\
\hline 5 & 10 & 43.9 & 44.5 & $\begin{array}{r}1 \\
+\quad 2\end{array}$ \\
\hline 6 & 10 & 23.4 & 20.3 & -13 \\
\hline 7 & 10 & 27.0 & 34.9 & +30 \\
\hline 8 & 10 & 19.6 & 19.6 & 0 \\
\hline 9 & 12 & 37.3 & 51.3 & +38 \\
\hline 10 & 15 & 16.0 & 19.4 & +19 \\
\hline 11 & 20 & 30.8 & 21.0 & -32 \\
\hline 12 & 20 & 35.1 & 41.0 & +17 \\
\hline 13 & 20 & 25.9 & 25.4 & 0 \\
\hline
\end{tabular}

Cases 3,4 , and 9 had transient ischaemic attacks; the remainder had dementia. 
in blood pressure or $\mathrm{PaCO}_{2}$, clearly indicates a cerebral vasodilator action of nicergoline in those cases. This action was obtained despite the presence of cerebrovascular disease in these patients.

Previous work in our laboratory indicates that the effect of nicergoline may have been greater than is demonstrated in these results (Palmer et $a l .$, 1977). In sequential measurements of cerebral blood flow at an interval of about 30 minutes under the general anaesthetic regime used in the present study, there was a fall in flow at the second measurement ranging from 0 to $46 \%$ (mean $24 \%$ ) in a series of 11 patients. Even under local anaesthesia an average reduction of $10 \%$ (range 0 to 27) at the second measurement of cerebral blood flow was evident in a series of 20 patients unless psychological activation continued throughout the period of study. This sequential fall may obscure part, or all, of any rise in cerebral blood flow caused by an administered pharmacological agent. The concept of the 'steady state' which has hitherto been restricted to physiological parameters such as $\mathrm{PaCO}_{2}$ and blood pressure must be extended to include the degree of activation of the brain. Studies of the effect of pharmacological agents must take into account the fall in cerebral blood flow during sequential measurements unless the brain is activated. Without attention to this point the effect of drugs on cerebral blood flow may well be underestimated.

The findings of the present study, therefore, indicate that nicergoline can produce an appreciable short-term increase of cerebral blood flow in patients with established cerebrovascular disease.

This work was supported by Advisory Services (Clinical and General) Ltd. Nicergoline was supplied by Farmitalia.

\section{References}

Arcari, G., Dosignotti, L., Fregnan, G. B., and Glasser, A. H. (1968). Vasodilating and alphareceptor blocking activity of a new ergoline derivative. British Journal of Pharmacology, 34, 700P.

Benzi, G., Manzo, L., De Bemardi, M., Ferrara, A., Sanguinetti, L., Assigoni, E., and Beste, F. (1971). Action of Lysergide, Ephedrine and Nimergoline on brain metabolizing activity. Journal of Pharmaceutical Sciences, 60, 1320-1324.

Olesen, J., Paulson, O. B., and Lassen, N. A. (1971). Regional cerebral blood flow in man determined by the initial slope of the clearance of intraarterially injected $133 \mathrm{Xe}$. Stroke, 2, 519-540.

Palmer, N. I., Thomas, D. J., MacGillivray, B. B., Du Boulay, G. H., Marshall, J., Ross Russell, R., and Symon, L. (1977). Variations in mean cerebral blood flow under anaesthesia at rest and during cortical activation. Stroke, 8, 269-271.

Wilkinson, I. M. S., Bull, J. W. D., Du Boulay, G. H., Marshall, J., Ross Russell, R., and Symon, L. (1969). Regional blood flow in the normal cerebral hemisphere. Journal of Neurology, Neurosurgery, and Psychiatry, 32, 367-378. 